\title{
As mídias, as instituições de saúde e a população: convergências e divergências na comunicação sobre a prevenção da dengue
}

The media, the health institutions and the population: convergences and divergences in communication concerning prevention of dengue

Los medios, las instituciones de salud y la población: convergencias y divergencias en la comunicación sobre la prevención del dengue

\section{Inesita Soares de Araújo}

- Doutora em Comunicação e Cultura pela Escola de Comunicações da Universidade Federal do Rio de Janeiro (ECO-UFRJ)

- Pesquisadora do Laboratório de Comunicação e Saúde (Laces) e do Instituto de Comunicação e Informação Científica e Tecnológica em Saúde (Icict), da Fundação Oswaldo Cruz

- Implantou e coordena o Programa de Pós-Graduação em Informação e Comunicação em Saúde (PPGICS) da Fiocruz

- Atuou na interface com o meio rural, particularmente com a agroecologia e, posteriormente, na interface com a saúde, incluindo a saúde indígena

- Líder do Grupo Comunicação e Saúde do Diretório do CNPq

- Coordenadora do GT Comunicación y Salud da Asociación Lationoamericana de Investigadores de la Comunicación (Alaic)

- Membro do Grupo Técnico de Comunicação e Saúde da Associação Brasileira de Pós-Graduação em Saúde Coletiva (Abrasco)

- Autora de A reconversão do olhar: prática discursiva e produção dos sentidos na intervenção social (2000) e coautora de Comunicação e saúde (2007)

- E-mail: inesita@icict.fiocruz.br 


\section{Resumo}

Apresenta-se uma pesquisa sobre a comunicação na prevenção da dengue. Com apoio em teorias da produção social dos sentidos, buscou-se compreender e comparar os discursos da mídia, das instituições de saúde e da população sobre a dengue. Foram analisados jornais e telejornais, fluxos de produção e circulação e conteúdos dos materiais informativos, além da realização de entrevistas com moradores de um conjunto de favelas. Os resultados incluem mapas das fontes e dos fluxos da comunicação sobre a dengue, bem como do fluxo de produção e circulação dos materiais das instituições. Entre as conclusões estão a circularidade dos discursos midiáticos e institucionais e a discrepância destes com os da população.

\section{PALAVRAS-CHAVE: COMUNICAÇÃO E SAÚDE • DENGUE • MÍDIA•SAÚDE}

\section{Abstract}

The text presents a research on communication in the prevention of dengue. Based on theories of social production of meanings, it was sought to understand and compare the discourses on dengue by the media, by health institutions and by the public. We analyzed newspapers and television newscasts, flows of production and circulation of informational materials, while also interviewing residents from a set of favelas (shantytowns). The results include maps of the sources and flows of communication on dengue and the flow of production and circulation of subject-matters of health institutions. Among the conclusions are the circularity of the media and institutional discourses and their discrepancy with those of the population.

\section{KEYWORDS: COMMUNICATION AND HEALTH・DENGUE FEVER • MEDIA • HEALTH}

\section{Resumen}

Se presenta una investigación sobre la comunicación en la prevención del dengue. Basándose en las teorías de la producción social de sentidos, se procuró comprender y comparar los discursos en los medios de comunicación, las instituciones de salud y la población sobre el dengue. Se analizaron los periódicos y los noticieros de televisión, flujos de producción y circulación de materiales informativos y además de la realización de entrevistas a residentes de un barrio periférico. Los resultados incluyen mapas de las fuentes y de los flujos de comunicación sobre el dengue, así como del flujo de producción y circulación de materiales de las instituciones. Entre las conclusiones se destaca la circularidad de los discursos mediáticos e institucionales y la discrepancia de éstos con los de la población. 
À noite, a mãe rezava com o filhinho de quatro anos: "Santo Anjo do Senhor, meu zeloso guardador, já que a ti me confiou a piedade divina, me rege, me guarda..." A criança ataIhou: "e me protege do mosquito da dengue". Iniciamos relatando esse fato, ocorrido em agosto de 2008, na cidade de São Paulo, que não foi naquele ano particularmente atingida pela epidemia de dengue no país, para evidenciar um ponto que tem centralidade neste texto: a participação dos meios de comunicação na construção dos sentidos públicos da saúde. O garotinho de quatro anos vê televisão, seus pais, sua professora, seus coleguinhas também veem. A ameaça da dengue, construída simbolicamente em redes nacionais, alça outro personagem ao panteão infantil dos perigos da vida, ao lado do bicho-papão, da bruxa, do lobo mau, do coringa... Representações do mal contra o qual se deve combater e pedir proteção.

A relação entre meios de comunicação e saúde e, mais especificamente, entre meios e prevenção epidemiológica tem sido objeto de crescente atenção dos que se dedicam a estudar os fenômenos midiáticos, tanto do campo da comunicação como do da saúde. A forma mais corrente de processar essa avaliação é a que busca aferir o que as pessoas recordam ou o que entenderam das mensagens veiculadas nos meios de comunicação com conteúdos informativos sobre determinada doença.

Este texto apresenta algumas conclusões de uma pesquisa que, a partir de pressupostos que acusam a insuficiência dos resultados produzidos por esse tipo de avaliação e compreendem diferentemente o processo de produção social dos sentidos, particularmente dos sentidos da saúde, procurou inovar metodologicamente, oferecendo algumas outras respostas sobre as inquietações da sociedade e dos setores voltados aos temas da saúde coletiva. O texto acha-se dividido em três partes. Inicialmente, abordamos dimensões contextuais: situando a pesquisa no espaço institucional, localizando a temática da dengue no conjunto das preocupações da saúde e tratando dos conceitos teóricos centrais. Em seguida, apresentamos a pesquisa, nas suas dimensões de tempo, espaço e metodologia. A terceira parte é dedicada aos resultados da pesquisa.

\section{CONTEXTOS}

\section{Lugar de fala}

O lugar de onde se fala estabelece alguns dos parâmetros que regem nossa fala, sendo, portanto um elemento relevante nas condições de produção da comunicação. O lugar de onde falamos é a Fiocruz (Fundação Oswaldo Cruz), instituição de saúde pública do Ministério da Saúde, formada por catorze institutos e centros de pesquisa, ensino, serviços e produção de vacinas e remédios. Na Fiocruz, nosso lugar é o Laces (Laboratório de Pesquisa em Comunicação e Saúde), que por sua vez integra o Icict (Instituto de Comunicação e Informação Científica e Tecnológica).

No Laces pesquisamos e ensinamos sobre comunicação e saúde. A multidimensionalidade da comunicação e a heterogeneidade dos processos sociais nos impõem desafios, que buscamos 
enfrentar: 1) descobrindo, apropriando e mesmo elaborando conceitos que nos aproximem dessa realidade multifacetada; e 2) experimentando e desenvolvendo métodos que permitam apreensão dos nossos objetos específicos, com suas características processuais, relacionais e transversais.

Em nossas pesquisas contamos com o frequente concurso de parceiros institucionais ou individuais, entre os quais gostaríamos de mencionar a pesquisadora Ana Paula Goulart Ribeiro (ECO-UFRJ), que esteve na gênese deste artigo, ao ter sob seus cuidados a análise de discursos que integrou a metodologia da pesquisa cujos resultados são aqui apresentados.

\section{A dengue, a saúde e a comunicação}

Mais de 2,5 bilhões de pessoas que habitam as regiões tropicais do planeta Terra correm o risco de contrair a dengue. Estimam-se em 100 milhões os casos anuais, no mundo, de febre dengue e 450 mil casos anuais da sua forma hemorrágica. Essa afirmação mostra bem a gravidade do problema que se apresenta ao campo da saúde.

No início da década de 1950, a dengue tornou-se uma causa importante de morbidade e mortalidade no mundo, após a ocorrência de algumas epidemias com crianças no sudeste asiático. Na década de 1980, o problema aumentou com epidemias no Brasil, na Bolívia, no Paraguai, no Equador e no Peru e, em fins de 1981, ocorreu no Brasil o primeiro surto da doença em que houve isolamento viral.

Já neste século XXI, em 2002 uma epidemia havia produzido devastação no país, com registro de quase 700 mil casos, particularmente no Rio de Janeiro, onde foram registrados mais de 249 mil casos. No biênio 2007-2008, a epidemia que atingiu o Rio de Janeiro e várias regiões do Brasil contribuiu para ampliar a preocupação com a dengue: ocorreram milhares de casos e centenas de mortes. Em 2008, só no estado do Rio de Janeiro foram 198.269 casos, com 242 óbitos notificados. Em 2011 foram registrados 697.998 casos no país, sendo 249.120 no Rio de Janeiro, com 134 óbitos $^{1}$. No momento em que este texto está sendo finalizado, em 2012, o boletim sobre a dengue que a Secretaria Municipal de Saúde do Rio de Janeiro emite semanalmente indica que até o dia 14 de abril já foram verificados 40.252 casos da doença² ${ }^{2}$.

Ainda que poucos, os dados acima nos permitem entender porque a dengue é, atualmente, considerada a arbovirose ${ }^{3}$ mais importante entre as que afetam o ser

\footnotetext{
${ }_{1}$ Fonte: Site do Ministério da Saúde / Secretaria de Vigilância Sanitária.

2 Fonte: Boletim Semanal da Dengue, 16/04/2012. Disponível no site da Secretaria Municipal de Saúde do Rio de Janeiro, www. rio.rj.gov.br/web/smsdc.

3 Um arbovírus é um vírus transmitido por artrópodes como os mosquitos. Podem causar doenças como a dengue, a febre amarela, a meningite, entre outras.
} 
humano e se apresenta como um grave problema de saúde pública, não só no Brasil, mas no mundo. Não existindo ainda uma vacina eficaz e segura, sua prevenção ocorre por meio do combate ao vetor, o mosquito aedes aegypti. A vigilância epidemiológica, nesse caso, compreende tanto a notificação de casos clínicos como a busca ativa das larvas do mosquito. A participação da população é considerada um dos fatores mais importantes na erradicação dos locais que sirvam como criadouros.

A dengue, como todos os demais agravos da saúde, é um fenômeno multidimensional e como tal exige que seja considerado de forma multidisciplinar e multissetorial. Entre as dimensões relevantes está a comunicacional, compreendendo-se aí o processo de produção, circulação e apropriação das informações sobre sua prevenção e seu controle.

Mas a dengue não é um "problema de comunicação": estando afeta ao campo das políticas públicas de saúde, é um problema complexo e demanda ações de pesquisa, desenvolvimento tecnológico, investimento público em infraestrutura e serviços etc. A comunicação é, neste caso e pelo nosso modo de ver, todo o processo que resulta na produção dos sentidos sociais sobre saúde e sobre a dengue em particular. Assim sendo, é crucial na possibilidade de implantação e apropriação das políticas públicas que visam à prevenção e ao controle da epidemia.

No entanto, a comunicação tem sido vista como um conjunto de instrumentos para disseminação da voz institucional, quase sempre configurando um rol de instruções sobre como a população deve agir em relação aos problemas de saúde. Mais recentemente, a partir dos anos 1990, o componente "mídia" adquiriu grande relevância, sendo mesmo muitas vezes considerado sinônimo de comunicação. A mídia produz reações apaixonadas no campo da saúde. Por um lado, representa uma de suas demandas, no sentido da aspiração de se ocuparem mais espaços de visibilidade pública. Por outro, é considerada uma antagonista, principalmente pelos pesquisadores e gestores que gostariam de ver retratados com mais fidelidade suas percepções e seus discursos sobre os temas da saúde e que recusam a pertinência e legitimidade de suas lógicas próprias de noticiabilidade. Por outro lado, ainda, os que fazem os meios de comunicação ressentem-se do hermetismo da abordagem dos pesquisadores e outros profissionais da saúde, da dificuldade de acesso à informação e da incompatibilidade dos ritmos vividos pelos dois setores (Araújo; Cardoso, 2007).

As epidemias da dengue, porém, como eventos que demandam um esforço coletivo e integrado para seu enfrentamento, vêm pondo em xeque os habituais posicionamentos e produzindo novas formas de articulação entre os meios de comunicação e as instituições de saúde. 


\section{Um olhar teórico (e suas reverberações metodológicas)}

O entendimento da comunicação como um processo social de produção, circulação e apropriação dos sentidos (Verón, 1980), no qual essas etapas não ocorrem de forma linear e unidirecional, mas por meio de um movimento multipolar, multidirecional e multidimensional, determinou os rumos metodológicos da pesquisa. Diferentemente das pesquisas de comunicação mais correntes na saúde, que objetivam avaliar a adequação do dito ao compreendido (ideal dos modelos de base transferencial, dominantes no campo), buscamos comparar os sentidos que emanaram dos enunciados midiáticos com aqueles dos materiais de comunicação direcionados à prevenção da dengue e, num segundo movimento, estabelecer uma contraposição com os expressos na fala das pessoas.

Esse procedimento pressupôs outros posicionamentos teóricos, que decorrem da abordagem produtiva do processo comunicativo: a partir do postulado da economia política do significante (Pinto, 1994), podemos dizer que esse processo caracteriza um mercado, que opera num nível simbólico e no qual as pessoas e comunidades discursivas (Maingueneau, 1993) negociam seu próprio modo de perceber e classificar o mundo. Nesse sentido, caracteriza-se uma concorrência simbólica pelo que Bourdieu (1989) chamou de "poder de fazer ver e fazer crer", que é, ao fim e ao cabo, o poder de constituir as realidades.

Algumas palavras são chaves no entendimento desse processo. A principal delas, a nosso ver, é contexto. A importância da noção de contexto é tamanha, para a comunicação, que Pinto (1995) chegou a afirmar que a capacidade de comunicar é a capacidade de contextualizar. Em outros termos, poderíamos afirmar que a contextualização é condição de produção dos sentidos sociais. Os fluxos incessantes de informações que percorrem as redes materiais e virtuais são co-determinados por contextos de natureza diversa, assim como os interlocutores que movimentam essas redes são seres situados na confluência e conjugação de vários contextos. Ou seja, os sujeitos e as relações sociais são constituídos num espaço, num tempo e numa conjugação de fatores que exercem coerções sobre seu modo de ser. Inesita Araújo (2002), em sua sistematização de um modelo de comunicação para políticas públicas, confere realce a quatro tipos de contexto, que foram privilegiados na pesquisa que ora relatamos.

O contexto textual fala da relação de contiguidade entre textos na mesma superfície espacial ou temporal. Refere-se às situações de circulação e traz a ideia de que a posição dos enunciados em relação aos que lhe são próximos constitui condição de produção dos sentidos possíveis. $O$ contexto intertextual, embora também se refira às relações entre textos, estas não dependem de proximidade física, ocorrendo seu efeito pela rede de semiose que é acionada a cada enunciação, que se nutre da memória discursiva particular dos indivíduos e coletividades. Esses dois contextos nos obrigam a descartar a análise dos textos como objetos autônomos e valorizam os processos de circulação e apropriação, entendidos como estratégicos na constituição dos sentidos sociais. 
O contexto existencial diz respeito à posição dos interlocutores num tempo e num espaço particular: sua história de vida, seus grupos de pertença, gênero, classe, idade, sua experiência anterior com o referente de cada ato comunicativo, sua história de relações com as instituições e as políticas públicas etc. Já o contexto situacional referencia o lugar de interlocução (Araújo, 2002) das pessoas. Em outros termos, o lugar nas relações sociais que os interlocutores ocupam no momento de cada ato comunicativo. Não é um lugar de fala fixo, definido pela condição social ou institucional de cada um, mas constituído em situação e sujeito a múltiplas variáveis que, ao fim e ao cabo, definem a legitimidade da fala de cada interlocutor e seu grau inicial de poder em cada relação, a partir do qual ele desenvolve suas estratégias enunciativas.

Os quatro contextos nos obrigam a considerar, metodologicamente, as dimensões de textualidade, historicidade, prática social e, fundamentalmente, o lugar de interlocução dos sujeitos da pesquisa.

O outro conceito-chave que mencionamos é legitimidade, a qual para nós é condição de possibilidade de qualquer comunicação, mas no campo das políticas públicas adquire uma importância enorme. As comunidades discursivas só conseguem disputar espaço no mercado dos sentidos sociais se forem reconhecidas como legítimas em sua enunciação. Então, legitimidade é condição de reconhecimento, enquanto reconhecimento é condição de apropriação. Apenas estamos traduzindo em outras palavras aquilo que Bourdieu (1989) nos ensinou: qualquer que seja o capital de um interlocutor, ele só se converte em capital simbólico quando reconhecido como legítimo, sendo o poder simbólico resultante da posse do capital simbólico.

A articulação do modelo produtivo de Verón (1980) à teoria do poder simbólico de Bourdieu (1989) e a noção de contexto como principal operador metodológico foram os principais norteadores da configuração teórico-metodológica da pesquisa em pauta.

A concepção de comunicação modela nosso olhar sobre a prática social. Assim, onde outros modelos veem apenas o desafio de informar adequadamente sobre os modos de controle do mosquito transmissor da dengue, podemos, sob outro olhar teórico, perceber o funcionamento de um amplo e disputado espaço de comunicação, no qual comunidades discursivas (mídias, instituições, movimentos sociais da saúde, pessoas), a partir de seus próprios contextos, produzem e disputam sentidos sobre a dengue. Onde alguns modelos percebem a língua como um repertório de códigos, com significados estáveis, portanto transferíveis e decodificáveis, nossa perspectiva vê a língua como espaço estruturante das relações de poder e entende que o sentido não é transferível, mas produzido pela conjugação de inúmeros fatores e contextos, sempre situados historicamente. Enfim, o entendimento da comunicação como um processo permanente de produção, circulação e apropriação dos bens simbólicos, resultando na produção social dos sentidos, tem consequências sobre a metodologia de pesquisa: por um lado, substitui a busca de fórmulas comunicativas eficazes, própria dos modelos transferenciais, pela busca de um conhecimento sobre como os sentidos são produzidos; por outro, leva em conta o circuito produtivo por inteiro. Foi o que tentamos fazer e que passamos a relatar. 


\section{PESQUISA}

\section{Tempo, espaço e objetivos}

A pesquisa "Avaliação da comunicação na prevenção da dengue" foi desenvolvida entre os anos de 2003 e 2007, na cidade do Rio de Janeiro, com apoio da Faperj Fundação de Amparo à Pesquisa do Estado do Rio de Janeiro (Faperj), por meio do Programa de Desenvolvimento e Inovação Tecnológica em Saúde Pública (PDTSP) da Fiocruz.

Coordenada pela equipe do Laces, com a participação, em alguns momentos, de outros pesquisadores da Fiocruz ou de centros de pesquisa ${ }^{4}$, seu objetivo principal foi testar um método de avaliação da comunicação nas políticas de saúde, especificamente na prevenção epidemiológica. O que se procurou foi contemplar três componentes da prática comunicativa na saúde que habitualmente são tratados isoladamente: o midiático, o da comunicação institucional e o relacionado à população (modos de apropriação dos dois anteriores). Assim, buscou responder às perguntas quanto aos discursos circulantes sobre a prevenção da dengue:

- $\quad$ O que os meios de comunicação falam e como falam sobre a dengue?

- $\quad$ O que falam e como falam as instituições? Como fazem circular sua comunicação?

- $\quad$ Como a população se apropria das informações e produz sentidos sobre a dengue?

\section{Metodologia}

Conduzimos a pesquisa em três movimentos paralelos: monitorando e analisando os dispositivos de enunciação de dois jornais impressos e dois telejornais; analisando materiais de comunicação das instituições de saúde que circularam no período estudado; obtendo a fala da população sobre a dengue. Vejamos cada um em separado.

\section{Monitoramento e análise da mídia}

De 2003 a 2006, nos períodos entre outubro e maio, monitoramos jornais impressos e telejornais, selecionados dentre os mais lidos ou assistidos pela população estudada. Assim, analisamos os jornais O Dia e Extra e, quanto aos

\footnotetext{
${ }^{4}$ No Laces, a pesquisa foi coordenada por Inesita Araújo. Izamara Bastos e Wilson Borges se dedicaram ao monitoramento da mídia e à produção de boletins, bem como auxiliaram na análise dos discursos. Valéria Monteiro fez o mapa das fontes e dos fluxos da comunicação (figura 4). Outros integrantes do Laces participaram em momentos diferentes, aos quais agradecemos. Ana Paula Goulart Ribeiro (ECO-UFRJ) conduziu a análise dos discursos. Teresa Neves (DAB/Ensp/Fiocruz) fez o mapeamento do fluxo dos materiais institucionais (figura 3).
} 
telejornais, o RJ TV (nas duas edições diárias) e o Jornal Nacional, todos da Rede Globo de Televisão. Sobre este material foi aplicada uma análise social de discursos, relacionando textos e contextos.

A escolha do período de monitoramento deveu-se ao fato de que, em geral, as ações de prevenção da dengue são intensificadas de novembro até fevereiro, período que corresponde, em média, ao pico da epidemia, podendo se estender dependendo do comportamento da doença. Os meses de verão são privilegiados porque fatores ambientais, como a maior incidência de chuvas e calor, estabelecem condições favoráveis para a proliferação do vetor nessa época do ano.

\section{Mapeamento dos fluxos e análise dos materiais institucionais}

Dentro da prática de controle e prevenção da dengue, são produzidos pelas instituições governamentais federais, estaduais e municipais materiais como cartazes, folhetos, cartilhas, outdoors, busdoors, anúncios televisivos, páginas de internet e outros. Para responder às perguntas sobre o que e como falam as instituições e como circulam sua comunicação, fizemos um mapeamento dos fluxos de produção e circulação desses materiais, do Ministério da Saúde (em Brasília) até a população, passando pelas Secretarias Estadual e Municipal de Saúde. Os materiais, todos produzidos por alguma dessas instâncias públicas, foram também analisados em seu conteúdo.

Figura 1 - Exemplos de materiais impressos analisados na pesquisa

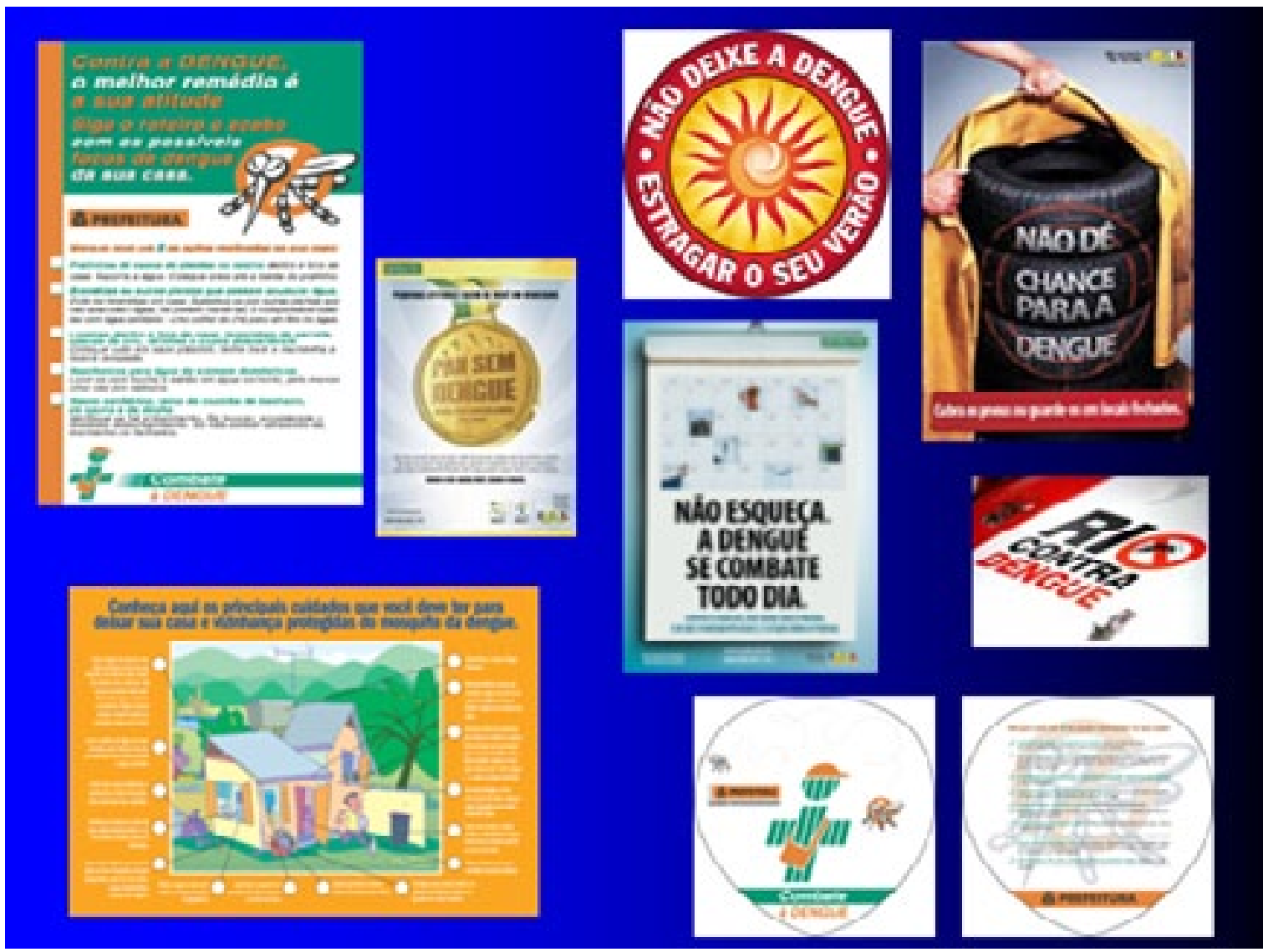


Figura 2 - Exemplos de materiais utilitários e virtuais analisados na pesquisa

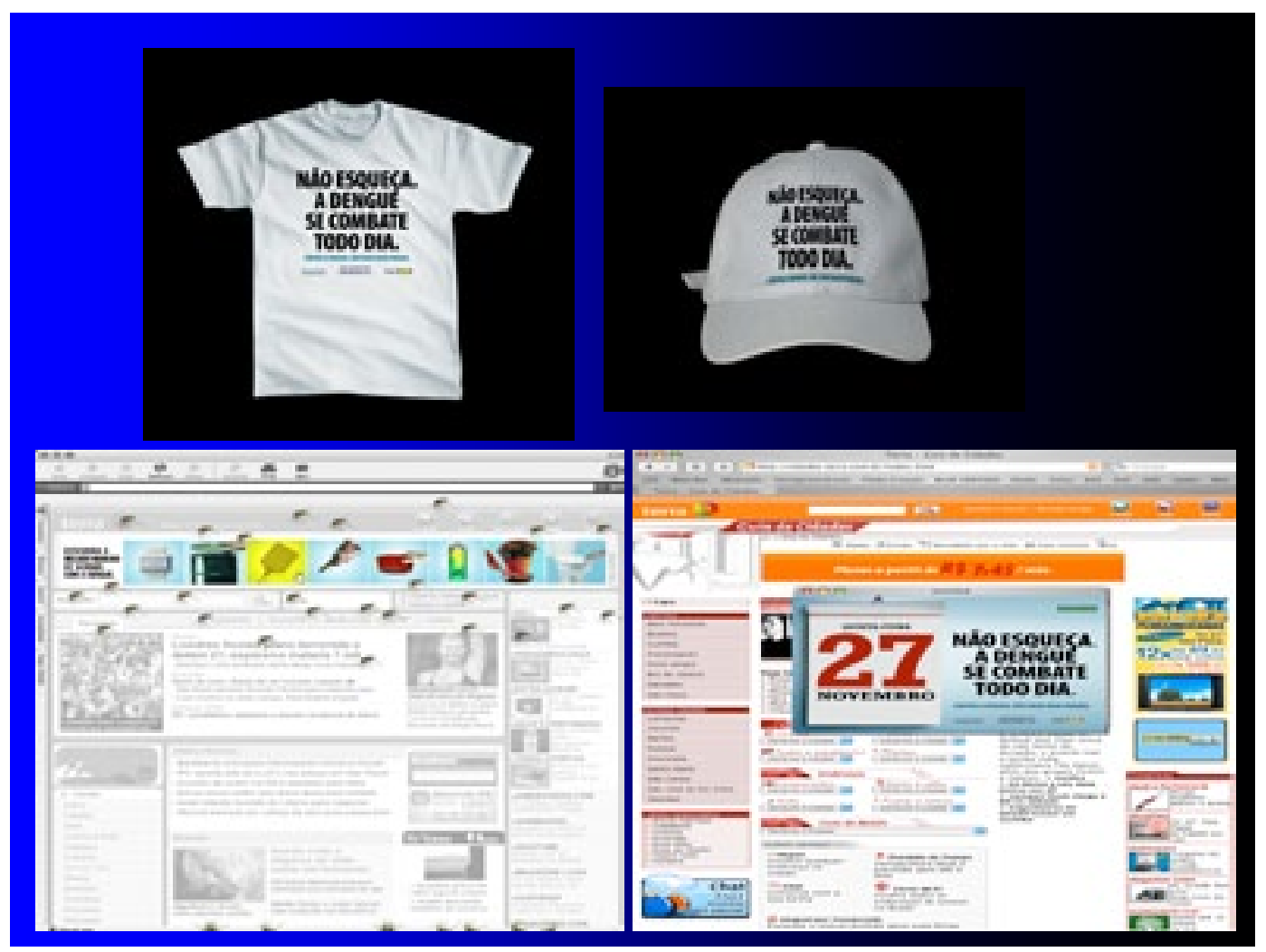

\section{Entrevistas com a população}

Buscamos responder à pergunta "Como a população se apropria das informações e produz sentidos sobre a dengue?" fazendo entrevistas nos locais de moradia e em um evento de saúde que congregou grande número de pessoas. Como base de população para a pesquisa, escolhemos um complexo de favelas no município do Rio de Janeiro, denominado Complexo de Manguinhos. Com população então de 53 mil habitantes, o complexo apresenta precárias condições de vida e graves problemas ambientais, o que acentua a existência de condições propícias à proliferação do aedes aegypti. Havia a intenção de, além das entrevistas, serem utilizados outros procedimentos mais interativos, apoiados na cultura local. No entanto, o agravamento da situação de violência impediu o desenvolvimento da pesquisa de campo, obrigando-nos a reduzir o número de entrevistas no local e a cancelar as outras estratégias metodológicas.

Mesmo assim, foram feitas oitenta entrevistas no local, tendo como modo de composição de amostra a rede de relações sociais, pela importância destas no processo de produção dos sentidos. Outras 164 foram realizadas em evento que contou maciçamente com a presença da população local ${ }^{5}$. As falas foram analisadas tendo como contraponto as análises feitas dos discursos e dispositivos de enunciação midiáticos e institucionais.

${ }^{5} \mathrm{O}$ "Fiocruz pra você", evento anual que promove a vacinação infantil contra a paralisia infantil com muita festividade e atividades lúdicas com dimensão educativa. 
A par da análise discursiva, foram realizadas duas cartografias: uma dos fluxos de produção e circulação dos materiais institucionais e outra, das fontes e dos fluxos de informação sobre a prevenção da dengue, a partir da identificação da própria população.

\section{ALGUNS RESULTADOS E REFLEXÕES}

A pesquisa produziu alguns resultados, entre os quais a proposta de um Observatório de Saúde na Mídia, atualmente estruturado e em atividade. Para este artigo, queremos destacar dois produtos - o desenho do fluxo dos materiais e o mapa das fontes e dos fluxos da comunicação sobre dengue - e tecer algumas reflexões que emanaram da comparação entre as três instâncias analisadas.

\section{Fluxos de produção e circulação dos materiais de comunicação}

A figura 3 mostra o desenho dos fluxos dos materiais produzidos pelo Ministério da Saúde e pelas secretarias estadual e municipal de Saúde do Rio de Janeiro, o caminho e instâncias de mediação desde sua produção até a chegada à população de Manguinhos. Como os fluxos são dinâmicos e as estruturas organizacionais passam por constante modificação, é importante precisar que o mapa reflete uma janela temporal do final de 2006 ao início de 2007, período em que foram feitas as entrevistas e sessões de trabalho com assessores de comunicação e setores técnicos envolvidos. No diagrama, as linhas contínuas representam situações de subordinação, enquanto as pontilhadas indicam a presença de diálogo e negociação. 
Figura 3 - Fluxos de produção e circulação dos materiais institucionais de comunicação para prevenção da dengue

\section{Fluxo institucional dos materiais de comunicação na prevenção da DENGUE}

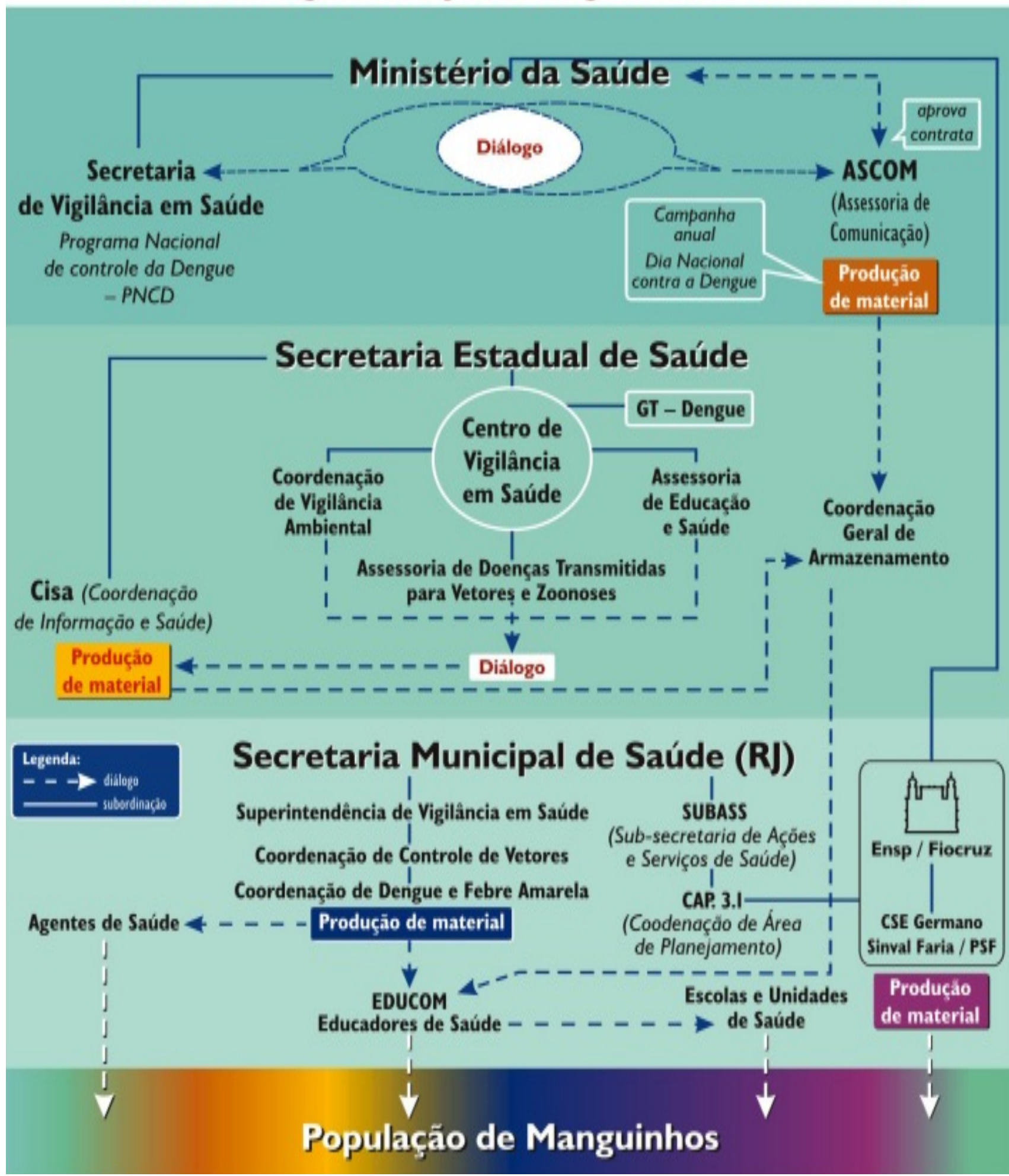

Autoria: Teresa Cristina Neves (DAB/Ensp/Fiocruz).

Fonte: Pesquisa "Avaliação da comunicação na prevenção da dengue". 
Na figura 3 se pode observar a pluralidade de instâncias por que passa um material, da decisão sobre sua produção até seu recebimento pela população a que se destina. Cada uma dessas instâncias agrega sentidos, em algum nível, a esse material. O percurso longo resulta frequentemente em um elemento nefasto aos objetivos das instituições, que é a perda de timing em relação ao evento ao qual pretende dar cobertura.

\section{Fontes e fluxos da comunicação sobre a prevenção da dengue}

No âmbito da população, obtivemos um mapa das suas principais fontes e fluxos de comunicação sobre dengue (figura 4), às quais acrescentamos inferências a partir da análise dos núcleos midiático e institucional. Em azul, podemos ver as comunidades discursivas mais fortes, citadas com mais insistência pelos entrevistados como fontes relevantes: encontramos a televisão, a vizinhança, o posto de saúde, os agentes comunitários de saúde, a Sucam (Superintendência de Campanhas da Saúde Pública $)^{6}$ e a escola. Podemos também apreciar um fluxo marcante de informação do núcleo institucional para o núcleo midiático.

Figura 4 - Fontes e fluxos de comunicação sobre a dengue para a população do Complexo de Manguinhos (Rio de Janeiro, RJ)

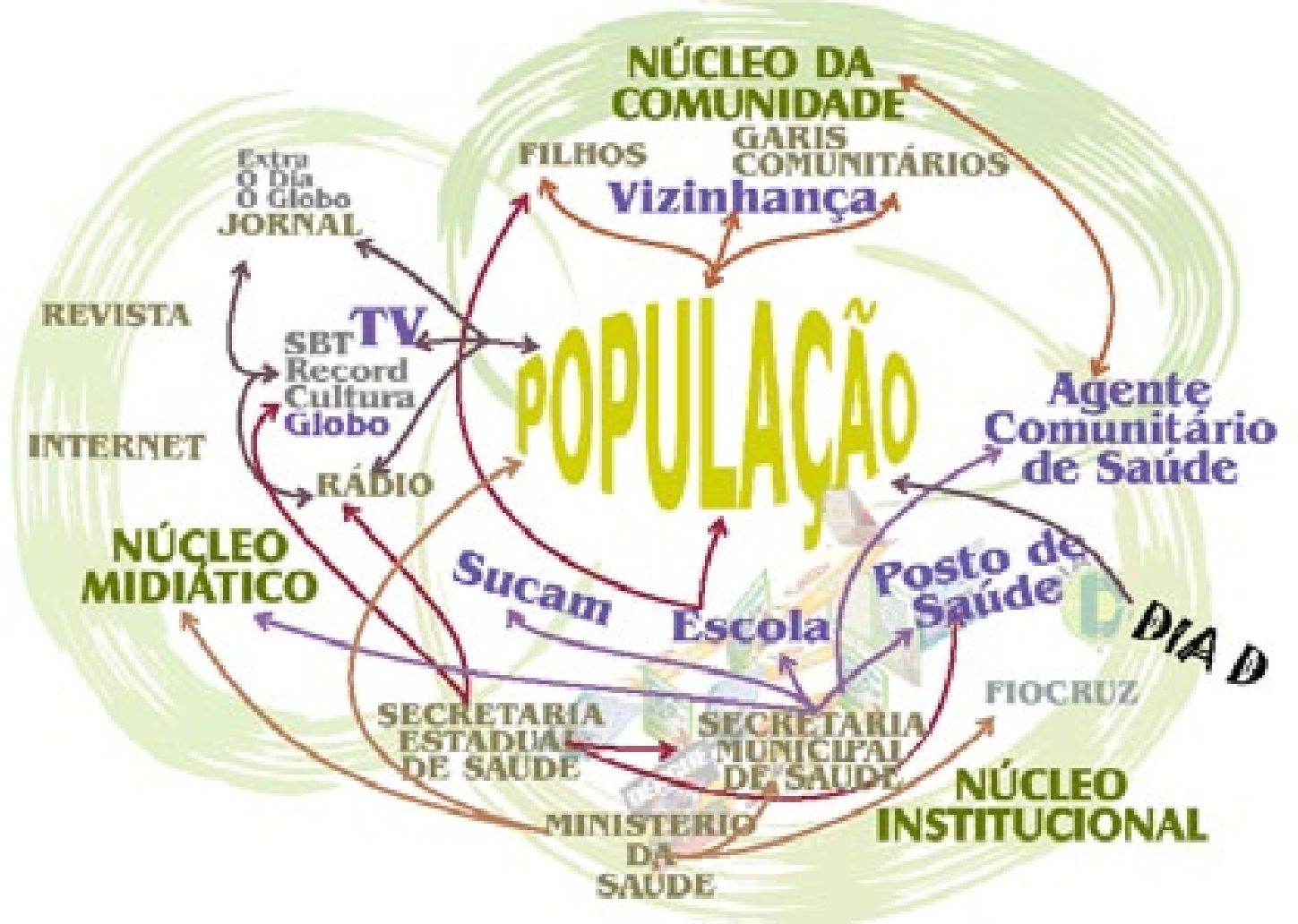

Autoria: Inesita Soares de Araújo.

Produção gráfica: Valéria da Silva Monteiro.

Fonte: Pesquisa "Avaliação da comunicação na prevenção da dengue".

\footnotetext{
${ }^{6}$ A Sucam foi extinta há décadas, mas a população continua citando seu nome, para referir-se aos serviços que a substituíram, embora no nível municipal. Como se trata de um mapa de um universo simbólico, consideramos importante manter a referência, que indica algumas questões no âmbito das políticas públicas, da construção de legitimidade, que se reflete fortemente na esfera discursiva.
} 


\section{Reflexões inquietas}

\section{Convergências ou... Meu querido inimigo}

A análise constatou uma acentuada convergência dos discursos das instituições com os da mídia. Esse resultado contradiz a percepção dos pesquisadores ede outros agentes do campo da saúde de que a mídia se contrapõe aos interesses da saúde. Se isto é verdade em outros temas, na prevenção epidemiológica da dengue, pelo menos no corpus estudado, isto não se verifica. Mídia e instituições de saúde falam a uma só voz, a primeira seguindo a pauta e amplificando as análises e orientações das segundas. Poder-se-ia levantar a questão se esse é um fenômeno restrito aos eventos epidemiológicos que requerem uma mobilização nacional para seu enfrentamento, permanecendo o antagonismo para outros assuntos, sendo este um tema para novas pesquisas.

\section{As similaridades se apresentam também por outros aspectos}

- O tema da dengue, como os demais, está subordinado às lógicas da noticiabilidade. Nos anos em que não há epidemia, não é noticiado. Da mesma forma, as instituições de saúde só se mobilizam e produzem comunicação quando explode uma epidemia.

- Tanto na mídia quanto nos materiais institucionais, constatamos um forte predomínio das falas autorizadas - instituições de saúde, médicos e cientistas. A fala dos demais atores, principalmente da população, só é utilizada para legitimar as falas autorizadas. Ou seja, as vozes da população são silenciadas e, na melhor das hipóteses, emolduradas e normatizadas.

- Ambas as instâncias discursivas desconsideram a existência prévia de um discurso higienista, que associa a doença à sujeira, operando o discurso preventivista de forma a-histórica e descontextualizada. Voltaremos a esse ponto mais adiante.

\section{A tv , mas também...}

Olhando a figura 4, veremos que não há uma hierarquia entre mídia, vizinhança, escola, posto de saúde, os agentes comunitários de saúde, os da prefeitura e a escola. Essas comunidades discursivas estão no mesmo nível de importância porque assim foi enunciado pela população. Os entrevistados falavam "da tv", mas também dos vizinhos, da tv, mas também do posto de saúde... Ou seja, a tv é muito importante como fonte de informação, mas ela não age sozinha, ela inter-age sempre com fonte interpessoais. 
Outro ponto que chama nossa atenção é a importância, para os entrevistados, de agentes da prefeitura, voluntários e outras figuras comunitárias como os garis, que têm seu lugar de interlocução empoderado porque orientam e agem concretamente, o que obriga a considerar a existência dessas instâncias mediadoras locais como estratégicas em qualquer política de controle da dengue e de qualquer outro agravo da saúde. No entanto, como a mídia enfatizou muito o papel dessas figuras, não é possível estabelecer até que ponto a percepção da população se faz de forma independente da construção midiática.

Emerge aí uma questão importante e interessante: a da impossibilidade de separar os discursos dos vários atores sociais dos discursos midiáticos, à qual voltaremos mais adiante.

\section{Divergências ou... Eu sou mais eu}

A análise confirmou a existência de discrepâncias entre a lógica que organiza a prática comunicativa das instituições e a lógica de apropriação da população dessa comunicação. Entre elas:

- A abordagem conferida pelos materiais institucionais descontextualiza a dengue. Pautados pelos modelos transferencial da comunicação e normativo da saúde, eles apresentam um conjunto de informações sobre os procedimentos a serem adotados, acompanhados de convocação à ação. Em contrapartida, a população contextualiza a doença nas suas condições de vida e nas políticas públicas. A dengue é apenas uma das consequências das precárias condições de moradia, saneamento, coleta de lixo, educação e acesso à informação específica e contextualizada ${ }^{7}$.

- Os materiais partem de um "degrau zero", como se nenhuma comunicação tivesse havido até ali, nenhum saber tivesse sido elaborado, nenhum discurso tivesse circulado antes do seu. Agindo assim, entre outros equívocos, terminam por desconsiderar a existência de um discurso anterior construído solidamente por décadas pelas instituições de saúde, de caráter higienista, que associa doença a sujeira. Essa memória discursiva "age" sobre a informação nova, baseada em outra associação, a da doença com água limpa, ampliando o arco da formação do imaginário das pessoas, que, na falta de um debate que releve seus conhecimentos prévios, desenvolvem suas próprias inferências.

- A população sabe o suficiente para prevenir a dengue, mas tende a só agir nesse sentido quando é afetada de perto pela doença. Isso não ocorre apenas com a dengue, diga-se de passagem, nem só com as classes populares, sendo um fenômeno mais abrangente. De qualquer modo, aponta para a insuficiência dessa forma única de fazer comunicação, que é a informação massiva e descontextualizada.

\footnotetext{
7 Em outros termos, "determinantes sociais da saúde", conceito irreversível na saúde, mas que a comunicação parece desconhecer solenemente, assim como os determinantes não incluem a comunicação.
} 


\section{A "promiscuidade" discursiva}

Uma constatação da pesquisa que nos instiga é a da dificuldade e mesmo impossibilidade metodológica e analítica de distinguir os discursos das várias comunidades discursivas, tanto entre elas (em seus produtos) como na fala da população. O processo de crescente midiatização da sociedade (Sodré, 2002; Fausto Neto, 1990) e o fato de a mídia se apropriar tanto dos discursos institucionais como da fala da população produzem uma mútua constitutividade discursiva, fazendo com que os métodos disponíveis sejam insuficientes para deslindarmos essa trama discursiva e distinguirmos com nitidez o que é e o que não é midiático, o que provém das instituições ou de outras fontes.

Poderíamos, porém, perguntar: é importante saber isso, nestes novos tempos de convergência tecnológica, mas também de abertura de outros e potentes espaços de circulação de sentidos? Nossa tarefa precípua seria deslindar essa trama? Que vantagem isso nos traria, num mundo que se constitui cada vez mais dentro das lógicas midiáticas e virtuais? Por outro lado, que outras preocupações o campo da comunicação e saúde precisaria ter, nesse âmbito? Algumas respostas podem ser sugeridas, entre elas o desafio de compreender melhor o papel desestruturante das tradicionais vozes autorizadas que a internet vem tendo. Estamos falando, por exemplo, no "Dr. Google", que vem mudando a relação médico-paciente, do paciente não só dos planos de saúde, mas também do SUS. Ou nos blogs dos portadores de patologias, de onde não só se reivindica, mas se questionam os discursos preventivista e da promoção da saúde, dominantes na saúde pública. A "Gato-Net" é hoje uma realidade contundente nas favelas, assim como a inclusão digital feita pelas lanhouses, e este é um movimento que cresce celeremente (provavelmente, se a pesquisa fosse repetida hoje, o mapa das fontes e dos fluxos traria a internet entre as instâncias mais citadas). Poderíamos também pensar na necessidade de estudos sobre o modo pelo qual as instituições de saúde vêm ocupando os espaços virtuais, aparentemente em grande medida reafirmando ali as velhas práticas centralizadoras da fala e prescritoras de comportamentos.

Nesse sentido, acreditamos que a perspectiva teórica da produção social dos sentidos, fortalecida por uma análise social de discursos que aceite o desafio dos novos tempos, apresenta-se como elemento central nesse esforço de compreender os processos atuais de constituição dos sentidos da saúde e nos ajudar a agir produtivamente sobre eles.

\section{CONSIDERAÇÕES FINAIS}

Os achados da nossa pesquisa apenas se aproximam do muito que precisamos compreender dos processos de produção social dos sentidos sobre saúde, bem como da identificação dos incontáveis discursos circulantes. A própria mídia dá lugar a enunciados que emanam dos mais diversos lugares, assim como outros locais se constituem como espaços de circulação de uma fala que ora concorre e ora é sinérgica com aquelas aqui analisadas, como a os laboratórios, a das escolas etc. Por outro lado, algumas de nossas constatações apenas reafirmam, em outras bases, o que já se sabia e já foi amplamente criticado. 
O mapa do fluxo de produção dos materiais nos mostrou um cenário de grande investimento institucional numa prática que já se esgotou. Eles são a face mais visível da comunicação de viés campanhista, de natureza prescritiva e normativa, produzida centralmente, que ignora as forças vivas da sociedade, as quais poderiam, se consideradas numa estratégia redistributiva do poder de falar e ser ouvido, trazer à cena outras vozes, outros saberes e outras histórias, habitualmente não percebidas ou consideradas dissonantes.

Uma estratégia como essa levaria a dialogar com outros discursos circulantes, permitindo contemplar a informação epidemiológica local, que seria talvez o maior fator mobilizador da ação coletiva em prol do controle epidemiológico. Por outro lado, criaria melhores condições para a efetivação de um debate nacional envolvendo não só os pesquisadores, sanitaristas, médicos e gestores, mas também, e sobretudo, a população mais pobre, em geral a maior vítima das epidemias.

\section{REFERÊNCIAS}

ARAUJO, Inesita Soares de. Mercado simbólico: interlocução, luta, poder. Um modelo de comunicação para políticas públicas. Tese (Doutorado em Comunicação e Cultura) - Escola de Comunicação, Universidade Federal do Rio de Janeiro, 2002.

A reconversão do olhar: prática discursiva e produção dos sentidos na intervenção social. São Leopoldo: Ed. Unisinos, 2000.

ARAUJO, Inesita Soares de; CARDOSO, Janine Miranda. Comunicação e Saúde. Rio de Janeiro: Ed. Fiocruz, 2007.

BOURDIEU, Pierre. O poder simbólico. Lisboa: Difel, 1989.

FAUSTO NETO, Antônio. Fragmentos de uma "analítica" da midiatização. Matrizes, Rio Grande do Sul, v. 1, n. 2, p. 89-105, 1990.

MAINGUENEAU, Dominique. Novas tendências em análise do discurso. Campinas: Pontes, 1993.

PINTO, Milton José. As marcas linguísticas da enunciação: esboço de uma gramática enunciativa do português. Rio de Janeiro: Ed. Numen, 1994.

Comunicação \& discurso: introdução à análise de discursos. São Paulo: Hacker Editores, 1999.

SODRÉ, Muniz. Antropológica do espelho: por uma teoria da comunicação linear e em rede. Petrópolis: Vozes, 2002.

VERON, Eliseo. A produção do sentido. São Paulo: Cultrix, 1980.

Recebido em: 22.04.2012 / Aceito em: 23/05.2012 